\title{
Does personality matter? An international study of sign language interpreter disposition
}

The International Journal for Research trans-int.org

\section{Karen Bontempo}

Macquarie University, Australia

karen.bontempo@mq.edu.au

\section{Jemina Napier}

Heriot-Watt University, Scotland

J.Napier@hw.ac.uk

\section{Laurence Hayes}

Eastern Kentucky University, USA

laurence.hayes@eku.edu

\section{Vicki Brashear}

Eastern Kentucky University, USA

vicki.brashear@eku.edu

DOI: ti.106201.2014.a02

\begin{abstract}
This article describes the results of an international research collaboration. The aim of the study was to identify the dispositional traits of interpreters that may be predictive of occupational performance. Empirically, general cognitive ability has been shown to be highly predictive of job performance across most occupations and is considerably more predictive than non-cognitive factors. The cognitive complexity of the task of interpreting is irrefutable, and it is likely there is a strong link between an interpreter's level of competence and his or her general cognitive ability across a number of important cognitive domains. The personalityperformance link is more ambiguous in an organisational context however, although intuitively dispositional traits are likely to play a role in interpreter education and training, and in interpreting practice. Drawing on literature from organisational psychology, personality psychology, interpreting and translation, and applied linguistics, an online survey methodology was developed to explore interpreter disposition and competence. The questionnaire incorporated reliable and valid tests of personality constructs including 'The Big Five' (openness to experience; conscientiousness; extraversion; agreeableness; and neuroticism), as well as constructs of perfectionism and self-esteem. The survey received 2193 responses from interpreters residing in 38 different countries, and is the largest international study of sign language interpreter personality ever undertaken. The results reveal clear patterns in regard to personality factors that predict interpreter performance. Based on the data collected in this global study, and the growing body of scholarly work in this area, the personality factors that appear to have predictive value for interpreters will be outlined, addressing possible implications for both pedagogy and practice in the profession.
\end{abstract}

\section{Keywords:}

Sign language interpreter, personality, disposition, aptitude, cognitive ability, interpreter competence. 


\title{
1. Introduction
}

In various textbooks on signed language interpreting, a range of personal 'attributes' or 'qualities' are identified that signed language interpreters ought to have. These include flexibility and self-discipline (Neumann Solow, 1981, 2000); good attention span, stamina, tactfulness, good sense of humour and good judgment (Frishberg, 1990); mentally and emotionally able to do the task (Humphrey and Alcorn, 1996); people (interpersonal) skills; and emotional skills such as self-awareness, self-control, selfmotivation, empathy, confidence, flexibility, reliability, self-discipline, resilience, humility (Napier et al., 2006, 2010).

In one textbook, Stewart, Schein and Cartwright (1998) discuss the 'psychology' of the interpreter, and note that:

\begin{abstract}
Interpreter education programs play a major role in helping interpreters achieve control over their reactions, but these programs alone cannot overcome every personality trait that interpreters bring with them and later interject into their work. In recruiting potential interpreters, education programs need to pay attention to their student's personalities as well as to their academic backgrounds and cognitive abilities. Emotional stability and the ability to control adverse reactions should be considered in selecting interpreters (p.75).
\end{abstract}

The recommendations above for the necessary psychological qualities of interpreters were made based on the intuitions of the authors as interpreter practitioners and educators. But was there any empirical evidence in support of their beliefs? The earliest study of signed language interpreters' personality traits was conducted by Jerome Schein (1974), who found that a cluster of personality characteristics, such as being independent, enjoying being the centre of attention, and not being too rigid, correlated with deaf people's perceptions of more or less skilled interpreters.

In their book Stewart, et al. (1998) acknowledged that (at that time) the psychological study of interpreting was a neglected topic. In the last decade, however, we have seen an exponential increase in the amount of empirical research on signed language interpreting. Research studies have drawn on a range of disciplines, including education, sociology, linguistics and psychology, and have explored various aspects of signed language interpreting processes and products (see Leeson, 2008, Metzger, 2006, Napier, 2011b, 2012, Grbić, 2007, Hale and Napier, 2013, for an overview).

Signed language interpreting studies that have drawn on psychological constructs and methodologies, and a range of existing psychological test batteries, have examined various traits, skills and abilities in an attempt to determine whether interpreting skills can be predicted and therefore taught. Studies have focussed on: cognitive reasoning abilities and other personal characteristics (Rudser \& Strong, 1986); cognitive, motor, attention, and personality attributes (Seal, 2004), perceptual-motor skills, cognitive skills, and personality factors (Gomez et al., 2007); cognitive abilities (Macnamara, 2009, Macnamara et al., 2011); cognitive performance parameters and motivational personality traits (Shaw, 2011); emotional stability, goal orientation and self-efficacy (Bontempo \& Napier, 2011); and working memory capacity (Wang, 2013; Wang \& Napier, 2013).

All of these studies have identified that there are various psychological factors that appear to be predictors of performance in signed language interpreting. In particular, the research has shown that some personality traits may be responsible for differentiating highly skilled from less skilled interpreters and may therefore be predictive of individuals' future interpreting skills if incorporated into interpreter program admission testing or career aptitude testing. 
However, each of these studies concentrates their analyses on groups of signed language interpreters in individual countries: the United States (US) (Seal, 2004; Macnamara, et al., 2011), Spain (Gomez, Molina, Benitez, \& Santiago de Torres, 2007), and Australia (Bontempo \& Napier, 2011; Wang, 2013; Wang \& Napier, 2013), with the number of participants ranging somewhere between $28-110$ individuals. The only exception is a study by Shaw (2011; Shaw \& Hughes, 2006), who collected data and drew comparisons between the US and four other European countries. Her research, however, concentrated on sign language interpreting students and what traits to identify in order to appropriately select students into interpreter education programs, rather than studying the personality traits of credentialed interpreters.

This study is therefore timely and unique for three reasons: (1) it directly compares the personality characteristics of signed language interpreters worldwide across 38 different countries, and (2) it compares professional working signed language interpreters (rather than students) across those countries; and (3) it is the largest comparative study of signed language interpreter personality characteristics ever conducted, with a participant sample of over 2,000 interpreters.

Our interest in studying interpreter personality came from our observations and discussion as signed language interpreter educators and researchers. Our goal in conducting this study was to build a profile of the personality dimensions and dispositional traits of the signed language interpreter population that could be considered to be most predictive of occupational performance. In particular we were interested in exploring the following research questions:

- Does personality play a role in predicting job performance for signed language interpreters?

- If so, which aspects of personality are most predictive?

- And: can a profile be built to screen for signed language interpreter occupational suitability?

Drawing on literature from organisational psychology, personality psychology, interpreting and translation, and applied linguistics, a survey instrument was developed to explore interpreter disposition and interpreter performance. The questionnaire incorporated established reliable and valid tests for personality, and measures to describe career success. The results reveal clear patterns in regard to dispositional qualities that predict interpreter performance. Based on the data collected in this global study, and the growing body of scholarly work in this area, this paper will outline the personality factors that appear to have predictive value for interpreters, addressing possible implications for both pedagogy and practice in the profession.

\section{Personality and aptitude}

In giving consideration to how personality traits may be a predictor for performance in interpreters, essentially what we are interested in is whether we can predict a person's aptitude for developing the necessary skills required to successfully perform as an interpreter. If, for example, an applicant to an interpreter education program demonstrates the right aptitude, then would we able to predict whether they are more likely to respond to the training they will receive throughout their program?

The concept of aptitude is closely related to concepts of readiness, suitability, susceptibility and proneness (Snow, 1992). The implication is that there will be a predisposition for a specific response by a person to some situation. If someone demonstrates the potential for a particular skill, this 
means that they demonstrate an inferred quality that makes possible the further development of that skill, given specified conditions.

Therefore, aptitude suggests an initial state for a person that influences their later development. This means that it is possible to forecast the probability of success under certain circumstances; for example, under certain learning conditions, with certain instructional strategies, in certain work contexts and so on. Aptitude for interpreting is not limited to linguistic or cognitive factors, but may also be influenced by personality traits, that is, whether you are the kind of person that is open to learning and developing certain skills.

Determining aptitude for future skills requires identifying key elements of that skill and testing for the elementary underlying abilities. If the skilled behaviour builds on these elementary abilities, they should be present even in the absence of skilled behavior, and should be measurable (Timarová and Ungoed-Thomas, 2008). Whilst general cognitive ability plays a key role in the development of such abilities (Schmidt \& Hunter, 1998), personality also influences aptitude (Bontempo \& Napier, 2011).

Personality is a mixture of values, temperament, coping strategies and motivation (among other things). A personality trait is a habitual way of thinking or doing in a variety of situations. An increasing body of research suggests that personality traits are strongly influenced by genetics (Bouchard \& Loehlin, 2001). In other words, people are born with at least the general outline of their personality traits already laid out for them. That does not mean that one cannot change, it just means that it may be difficult to change to any great extent, and also that personality is relatively stable over time (Judge et al., 1999).

Longitudinal studies show that the same individual even in two vastly different contexts separated by many years remains recognisably the same person (Nave et al., 2010: 9). There is some room for personality change in childhood, adolescence and early adulthood as people transition and are influenced by school, career, marriage, etc., but not a great deal changes over time especially once an individual reaches adulthood. Temperament at that point is largely enduring. Personality traits differ from individual to individual, and personality dimensions influence behaviour, therefore leading to the potential to predict patterns of behaviour in certain contexts, such as in the vocational arena.

Personality research published in recent years demonstrates a clear, generalizable and convincing relationship between personality and occupational performance (Barrick \& Mount, 2005; Barrick et al., 2001). Ones et al. (2007) suggest personality constructs can be used to explain specific attitudes, behaviours and performance in an occupational context. Notably, the role of personality in successful completion of courses of study and skill acquisition (Oakes et al., 2001); job performance (Judge et al. 1999); and career success (Bozionelos, 2004), cannot be underestimated. An individual's preferences and desires evidently influence person-vocation fit (Reeve \& Heggestad 2004), and their "adaptability, positive relationships, openness to experiences, and social and psychological capital" (Fouad 2007: 556) impact on career exploration. Ultimately, individual personality differences do relate to outcomes in study and at work.

Drawing on the research on personality, there is a specific body of work that has explored personality and achievement in second language acquisition (SLA). For example, evidence strongly suggests anxiety is part of the framework of personality variables that impact on SLA. Dörnyei (2005) notes that the second most important indicator of success in SLA (after age of learner), is having an aptitude for SLA. In terms of aptitude, it has been found that anxiety impedes language learning, and also that anxiety is a predictor of achievement in SLA courses (Gardner et al., 1976). 
Research has shown that: there are significant negative correlations between anxiety and course grades (MacIntyre \& Gardner, 1991); that anxiety impairs the quality of language task performance (Eysenck, 1979; Holroyd \& Appel, 1980); that language anxiety is accurately recorded through selfrated proficiency and actual proficiency rating scales (Gardner et al., 1984); and that recursive relations exist among anxiety, cognition and behaviour in students on language learning courses (MacIntyre, 1995).

Language learners and interpreting students have a great deal in common as they are required to engage cognitively in language learning processes. Given that interpreting students today are less likely to be natural bilinguals and more likely to be drawn from language courses (Zannirato, 2008), it is intuitive to expect many of the same issues found in SLA students, would also be found in interpreting students. So, we might want to seriously consider anxiety, or even neuroticism (emotional stability at the positive end of the spectrum), in assessing aptitude for interpreting, but what other factors need to be included in determining aptitude for interpreting, particularly in relation to personality variables?

Assessing aptitude for interpreting. Effective recruitment and selection is difficult for the sign language interpreting field to do without a clear and comprehensive framework for appreciating the relationships between knowledge, skills, abilities and how these may impact on job performance. Job performance is a multi-dimensional construct and can be measured in many ways. Motowildo et al (1997) argue general cognitive ability, task knowledge and task skills are related to task performance, whilst personality variables, contextual knowledge and contextual skills are linked to contextual performance in a job. Further, task performance and contextual performance are both integral to overall successful job performance.

In the case of signed language interpreters, this would mean that an individual possesses sufficient general cognitive ability to perform the task of interpreting, for example, the ability to learn, perceive, understand, process, evaluate, remember, manipulate language and so on. Essentially he or she has the intellectual resources required to perform the job, that is, an appropriate level of verbal comprehension, fluency, perceptual speed, spatial orientation, number facility, general reasoning, problem recognition, working memory etc. (Guion \& Highhouse, 2004).

In addition, it would be expected the interpreter has task-related knowledge such as knowing the principles and procedures related to the function of the job, including the code of ethics for example; and taskspecific skills such as the technical linguistic skill needed to perform the task of interpreting to the standard required, a knowledge of the vocabulary of the setting, and so on. These fore-mentioned elements influence task performance, and are clearly essential for performing the job of interpreting.

On the other hand, as previously described, personality refers to a mixture of values, temperament, coping strategies - traits that are predictable, enduring and that influence behaviour and reactions in a variety of situations. Contextual knowledge refers to knowledge of how to act in various situations - how to cooperate with people and interact professionally. Contextual skills are the skills involved in managing those interpersonal relationships and behaving effectively in a variety of environments. Personality, contextual knowledge and contextual skills impact on contextual performance. Contextual performance "refers to aspects of performance unrelated to specific tasks" (Guion \& Highhouse, 2004: 60). In regard to interpreting this might mean being a good role model for the profession, mentoring others, being punctual, professional and flexible, and other valued work behaviours that are not task-specific to the job of interpreting per se. To attain successful job performance, both task 
performance and contextual performance at effective levels would be expected from a professional interpreter.

Indeed, Kalina (2002) notes that an assessment of the quality of a performance by an interpreter cannot be limited to his or her interpreted output alone. Other aspects such as "the interpreter's appearance and general conduct during and around conferences, booth manners, discretion, commitment to preparation and debriefing, further training" (p. 124) are all also factors of consideration in regard to making an assessment of interpreter quality.

Whilst general cognitive ability, task knowledge and task skills are clearly the priority for being able to interpret successfully, neglecting the smaller, but nevertheless important, role that personality, contextual knowledge and contextual skills likely play in efficient acquisition of the interpreting skill and in effective job performance in a variety of work settings is naïve. Overlooking aspects related to contextual performance and concentrating only on some limited task performance elements, typically only the technical skills, in screening tests at program admission time, and on interpreter education programs, or in the workplace seems very shortsighted when there is more to the picture for successful occupational performance as an interpreter. In addition, applying a combination of predictors to determine performance outcomes has more practical utility and is more valid than a single predictor alone (Schmidt, 2002).

Early research on aptitude for interpreting and admissions screening research was based on (spoken language) conference interpreting (ArjonaTseng, 1994; Gerver et al., 1984; Lambert, 1991; Moser-Mercer, 1985, 1994, 1989; Russo, 1993; Russo \& Pippa, 2004). Regardless of the growing body of work in this area, concerns have been expressed by interpreter researchers and educators about the reliability and validity of approaches to program admission testing (Dodds, 1990, (Bontempo \& Napier, 2009; Sawyer, 2004; Timarová \& Ungoed-Thomas, 2008). There is currently a high level of interest in furthering research in the area of interpreter aptitude, but still only limited aptitude research is available regarding signed language interpreters.

It would seem that many current interpreter education program admissions tests are tests of ability rather than aptitude, but have high face validity, meaning they appear to assess the skills and abilities we want them to assess, but often in reality they do not offer reliable or valid results in terms of student outcomes on course (Bontempo \& Napier, 2009; Timarova $\&$ Ungoed-Thomas, 2008). The admission tests are often developed intuitively by interpreter educators based on their experience of teaching a range of students, but as interpreter educators often do not have a background in educational or psychological measurement, and no data is typically kept to check reliability and validity of the measures of the tests once they are developed, the tests may in fact not be accurate or robust measures of aptitude (Bontempo \& Napier, 2009; Campbell and Hale, 2003).

Although personality characteristics for success in signed language interpreter education courses have been explored from the student perspective (Stauffer \& Shaw, 2006), one of the huge dilemmas in interpreter education at present is that a potential interpreting student might succeed against the observational evidence that initially convinces us that they will not. The opposite is also true - candidates expected to do well based on program admission screening results, may not pass a final interpreting examination, for a host of reasons (Bontempo \& Napier, 2009). This situation makes it difficult to justify the investment of resources in screening and admission testing when even some of those students with initially promising signs turn out unable to achieve in the end.

Overall, our current screening and testing for interpreting aptitude is relatively poor: we do not collect and publish evidence on the processes and 
outcomes, and there is little evidence to suggest that there is any (predictive) validity in what we are doing (Clifford, 2005). Yet, interpreter educators at least, would agree that we need and want screening of this nature to justify student recruitment and selection within our institutions, as evidenced by the papers presented at an international symposium on interpreting aptitude that formed the basis of a special volume on the topic in the journal Interpreting (Bontempo \& Napier, 2011; Macnamara et al., 2011; Pöchhacker, 2011; Russo, 2011; Shlesinger \& Pöchhacker, 2011; Timarová \& Salaets, 2011).

Thus, if it is possible to develop a definitive profile of the personality dimensions and dispositional traits of the signed language interpreter population that could be considered to be those most predictive of occupational performance, and therefore a way of determining aptitude, these predictive constructs could be built into screening measures for program admission interviews and tests. The information regarding interpreter personality could also be used to support students throughout their interpreter education program, manage and support interpreter employees; and meet on-going training needs of interpreters.

The profile could also inform mentoring practices, team interpreting practices; and provide interpreter practitioners, employers and educators with relevant information to prevent occupational overuse injury by clarifying the relationship between personality and workplace stress, coping strategies, susceptibility to vicarious traumatisation, and to manage productivity and performance (including counterproductive behaviour), suggesting broader application in the interpreting field beyond admission testing.

\subsection{Constructs}

In order to measure the personality dimensions and dispositional traits of signed language interpreters working around the world, this study drew on existing valid and reliable psychometric tools:

- Items were drawn from the International Personality Items Pool (IPIP) to measure the 'Big Five' (Goldberg, 1990; McCrae \& Costa, 1999, 2003) - openness to experience, conscientiousness, extraversion, agreeableness and neuroticism (OCEAN);

- Additional items from the International Personality Items Pool (IPIP) were extracted to measure perfectionism (Hewitt \& Flett, 1991; Rice \& Slaney, 2002); and

- The Rosenberg Self-Esteem Scale was included to measure selfesteem (i.e., judgments of self-worth or value based on feelings of efficacy) (Rosenberg, 1965; Watson et al., 2002).

As noted, the 'Big Five' considers the broad personality constructs of:

- openness to experience;

- conscientiousness;

- extraversion;

- agreeableness;

- and neuroticism / emotional stability

(The latter is described inter-changeably in the literature as 'emotional stability' or as 'neuroticism').

Although a popular and useful form of measuring personality, the Big Five is not without flaws - the broadness of the constructs cannot capture a complete portrait of personality from individuals and instead offer a more global picture of personality. For this reason researchers will often hone in on specific aspects of a construct for further investigation. For the purpose 
and scale of this study, a global picture of the broader constructs was considered reasonable and appropriate, with only additional scales for perfectionism and self esteem added to the questionnaire to capture more information.

Empirical research evidence indicates the most significant broad personality construct that consistently predicts occupational performance is conscientiousness (Mount \& Barrick, 1998; Mount et al., 1998; Bozionelos, 2004). This appears logical, with conscientiousness as a construct including traits such as: achievement striving, self-disciplined, perfectionism, dutifulness, dependable, persistent, goal directed, organized, responsible, efficient, thorough, deliberate, and hard working (Judge et al., 1999). These are characteristics most employers and educators would probably want to observe in their employees and students.

The other construct that has revealed the most interesting findings is that of emotional stability, which is positively related to on-the-job success and work performance (Mount \& Barrick, 1998; Judge et al., 1999; Barrick et al., 2001). This broad construct is often also described from the negative pole as neuroticism. Sub-traits of this construct include: trait anxiety, insecurity, fearfulness, tendency towards depression/negative mood, high emotional reactivity, irritability and so on. Bozionelos (2004) adds that individuals who score high on this dimension often have low self-confidence and poor self esteem.

The other broad personality constructs of the Big Five have demonstrated significance only in selected occupations, for example, extraversion is found to be highly relevant in occupations with a significant social aspect to them, such as sales or management positions where interaction is a key part of the job (Barrick \& Mount, 2005). However, these other constructs (extraversion; openness to experience and agreeableness) have not demonstrated such consistent and significant findings across a wide range of occupations to the extent that the conscientiousness and emotional stability dimensions have displayed.

Another trait on the OCEAN scale that seemingly may be relevant to interpreters is openness to experience, which describes a personality dimension of cognitive style. Open people are intellectually curious - they also tend to appreciate art, and are more aware of their feelings than closed people. They tend to think and act in individualistic and nonconforming ways. Scores on openness to experience are only modestly related to years of education and scores on standard intelligence tests (Wikipedia, 2013). A characteristic of the open cognitive style is a facility for thinking in symbols and abstractions far removed from concrete experience - a characteristic that could be seen as highly useful for a sign language interpreter.

Table 1 provides an overview of the typical trait characteristics on the OCEAN scale.

There is a link between conscientiousness and perfectionism, however high levels of perfectionism can be debilitating and can lead to low self esteem and depression, and may also be linked to poor emotional stability. Indeed there are different types of perfectionism, with 'normal' perfectionists holding high personal standards but allowing for flexibility in some situations, in comparison to neurotic perfectionists who have a tendency to be disappointed in themselves unless their performance is absolutely perfect - generally an unachievable goal, leading to psychological dysfunction. The statistically significant relationships between self esteem, perfectionism, conscientiousness, emotional stability, anxiety and confidence described in the literature were of interest to us, hence the inclusion of perfectionism and self esteem constructs alongside the Big Five in this study. 
Table 1: Overview of typical OCEAN trait characteristics ${ }^{1}$

\begin{tabular}{|l|l|l|}
\hline Trait & Low scorers & High scorers \\
\hline Openness & Down to earth & Imaginative \\
& Uncreative & Creative \\
& Conventional & Original \\
& Uncurious & Curious \\
\hline Conscientiousness & Negligent & Conscientious \\
& Lazy & Hard-working \\
& Disorganised & Well-organised \\
& Late & Punctual \\
\hline Extraversion & Loner & Joiner \\
& Quiet & Talkative \\
& Passive & Active \\
& Reserved & Affectionate \\
\hline Agreeableness & Suspicious & Trusting \\
& Critical & Lenient \\
& Ruthless & Soft-hearted \\
& Irritable & Good-natured \\
\hline Neuroticism & Calm & Worried \\
& Even-tempered & Temperamental \\
& Comfortable & Self-conscious \\
& Unemotional & Emotional \\
\hline
\end{tabular}

Results of a meta-analysis by Judge and Bono (2001) revealed selfesteem and emotional stability are significant predictors of job performance, as well as job satisfaction. Mount et al (1998) found that jobs requiring a high degree of interpersonal interaction, cooperation and teamwork, were positively related to the specific personality constructs of emotional stability, conscientiousness and agreeableness. Further, the relationship between these personality predictors was even higher if the jobs involved little supervision of individual workers. It seems quite reasonable to consider these conditions might apply to the occupation of interpreting, so tools which could measure such disposition constructs were incorporated into the study design, along with the other considerations, such as measures of interpreter competence.

\subsection{Hypotheses}

Based on a review of the literature and normed results of the tests we were using, and our intuitions as interpreter practitioners, educators and researchers, we hypothesised that the study would reveal that more competent signed language interpreters:

1. have higher self-esteem;

2. rate higher in perfectionism;

3 . are higher in conscientiousness;

4. are less neurotic / more emotionally stable;

5. are more extroverted;

6. rate higher in openness to experience; and

7. rate higher in agreeableness.

\section{The study}

Fortunately everyone has a personality, and people are generally quite interested in participating in personality research, so we were fortunate that there was a great deal of interest in our study on an global scale. The study was conducted internationally through a collaboration between the authors

\footnotetext{
${ }^{1}$ Retrieved from http://www.kilfreud.com/OCEAN.jpg on 5 November 2013
} 
based (at that time) in Australia (Macquarie University) and the United States (US) (Eastern Kentucky University), by drawing on the existing psychological constructs as outlined above to develop an instrument to measure personality dimensions and dispositional traits of signed language interpreters, and to compare this profile with ratings of interpreter competence (successful performance).

\subsection{Instrument}

An online questionnaire was created using the survey software Survey Monkey (in English), and included 22 questions to collect demographic data, linguistic data, certification and training information, and ratings of perceived competence where respondents were asked to select an option on a likert scale offering five choices (from extremely competent to very little competence) to rate their level of competence as an interpreter (as perceived by self, Deaf community, and interpreter peers).

Additionally, various psychometric rating scales were used, which drew upon existing psychological constructs as described above (The International Personality Items Pool - the Big Five and Perfectionism \& The Rosenberg Self-Esteem Scale), to present respondents with over 100 statements about how they would describe themselves. Respondents were invited to describe how accurately each statement reflected their self-perception. They were asked to consider themselves as they generally were at that time and not as they wished to be in the future; and to describe themselves as they honestly saw themselves in relation to other people they know of the same gender and approximately the same age.

After reading each statement (such as 'make plans and stick to them', 'have frequent mood swings', 'start conversations', etc.), participants were asked to rate how accurately the statement corresponded to them $(1=$ very inaccurate, $5=$ very accurate). They were then presented with a further ten statements relating to self esteem to consider, and asked to select how strongly they agreed with the statements (such as 'on the whole, I am satisfied with myself') based on how they felt about themselves in general.

\subsection{Participants}

In total, 2,193 people responded to the survey, including both deaf and hearing signed language interpreter participants. Responses were received from working interpreters in 38 different countries - predominantly English speaking countries, including Australia, the US, UK, Republic of Ireland, Canada and New Zealand.

However, interpreters were also represented from Finland, Belgium, France, The Netherlands, Malaysia, China, Colombia, Nigeria, Israel, Argentina, Austria, Spain, The Philippines, Poland, Nicaragua, Japan, Kenya, Switzerland, Malta, South Africa, Ireland, Singapore, Norway, Germany, Brazil, Ghana, Sweden, Venezuela, Korea, and Greece. Such a breadth of responses make this study the largest international survey of signed language interpreters ever conducted.

\subsection{Process}

Ethics approval was received from the Macquarie University University Human Ethics Research Committee (ref. no HE01MAY2009-D06449) in April 2009, as well as from Eastern Kentucky University, and the study also received endorsement from the World Association of Sign Language Interpreters (WASLI).

The survey instrument was piloted with a small number of sign language interpreters $(\mathrm{N}=12)$ residing in Australia, New Zealand, the US and UK. It was then launched in the US at the conference of the Registry of Interpreters of the Deaf (RID) in August 2009, and in Australia at the 
National Conference of the Australian Sign Language Interpreters Association (ASLIA) later that same month. The survey was also widely promoted internationally and nationally through network and snowball sampling, for example, via the membership databases of WASLI and signed language interpreter associations in various countries, and through Facebook and the personal networks of the research team.

\subsection{Analysis}

The data had to be cleaned in order to ensure consistency across categories (e.g., with the description of interpreter qualification/accreditation). It was then coded in preparation for statistical analysis in SPSS. The data was analysed to note any areas of significance, using descriptive, parametric and non-parametric inferential statistical analysis.

\section{Results}

Given that a significant proportion $(1,429$, or $65 \%)$ of the 2,193 of the respondents were from the US and Australia, in this paper we concentrate on the results from these two countries. However, first we contextualize the US and Australian results by providing an overview of some of the most salient aspects of the global data.

\subsection{Global data}

The global demographic picture of the signed language interpreting profession reveals that, of the respondents to this survey, $89 \%(\mathrm{n}=1951)$ are female, and $11 \%(\mathrm{n}=242)$ are male $11 \%$. This supports the generally observed trend that signed language interpreting is a female dominated profession. Breaking down the results in the English-speaking countries, it can be seen that in Australia the number of male respondents was $15.5 \%$; in the US 10.9\%; Canada 6.6\%; and in the UK, it was $23 \%$. These findings are borne out in other literature reporting demographic surveys from Australia (Bontempo \& Napier, 2007; Napier \& Barker, 2003), the US (Cokely, 1981; Stewart et al., 1998), Canada (Schein \& Yarwood, 1990), and the UK (Brien et al., 2002).

On a global level, the most significant predictor of interpreter competence was self-esteem $(\mathrm{r} 2=.266)$, followed by openness to experience $(\mathrm{r} 2=.31)$, then much more moderately - perfectionism $(\mathrm{r} 2=.096)$.

In relation to the global data, looking at those interpreters who work freelance as compared to those that are employed full-time in-house for an agency, those who do freelance work are more self-confident and rate themselves more highly. Openness to experience, emotional stability, extraversion, and self-esteem were bigger predictors of competence in freelance interpreters.

When we examined the data of the English-speaking countries more closely, self-esteem was by far the biggest predictor across all the nations:

- Australia $(n=205)$ : self-esteem, then conscientiousness;

- US $(n=1224)$ : self-esteem, then openness to experience;

- Canada $(\mathrm{n}=150)$ : self-esteem;

- $\quad \mathrm{UK}(\mathrm{n}=123)$ : self-esteem;

- $\quad \mathrm{NZ}(\mathrm{n}=15)$ : self-esteem.

In analysing the differences between native and non-native signers we found openness to experience and emotional stability were more significant personality predictors in native signers, and all three competence ratings (self rated competence as an interpreter; self-rated level of competence as an interpreter as perceived by peers; and self-rated level of competence as an interpreter as perceived by Deaf community) were all significant in native 
signers. Essentially, native signers gave themselves higher ratings on all of these ratings of self-competence or perceived competence by others.

Native signers also rated themselves as having much higher levels of sign language proficiency than non-native signers, whereas non-native signers rated themselves more highly than native signers on spoken language proficiency. Further analysis of the data collected from these groups, found that there was less variability in sign proficiency ratings amongst the native signers, that is, they tended to all rate themselves quite confidently in their signing ability. There was much more variability in non-native signers and how they rated their sign language proficiency. The opposite was true for spoken language proficiency, with non-native signers being very confident and showing much less variability about their spoken language proficiency. All results were highly significant.

We examined reported ratings of interpreting competence that would be given by colleagues and by deaf people (as perceived by the respondent) and they each came out with the highest predictors identified as (a) self esteem, (b) openness to experience and (c) perfectionism (with colleague ratings including a distant fourth predictor - extraversion, but this was only a minor predictor). With ratings of sign proficiency, the exact same pattern of three predictors appeared in the same order as with ratings of interpreting competence. Spoken language proficiency ratings, however, were reversed in the following order of predictiveness: (a) openness to experience, and (b) self-esteem. Perfectionism did not appear at all as a spoken language proficiency predictor. Self-esteem and openness to experience accounted for $15 \%$ of the variance in language proficiency, which is reasonably high for personality variables.

These global results reveal that high self-esteem is the single biggest predictor of competence among signed language interpreters. This is probably not surprising given the nature of the job in many ways interpreters have to 'act' as other parties, often dealing with complex content in stressful circumstances - they need a great deal of resilience and confidence to maintain their sense of self in such an occupation. The broader literature on self-esteem suggests that poor self-esteem is related to greater levels of stress, depression, poor psychological well-being, poor psychological health, lower self-esteem and poor self-reported retrospective physical health (Dua, 1993). Furthermore, people with low self-esteem and emotional instability are more likely to experience diminished physical wellbeing (Kashdan et al., 1993), and be more prone to depression, anxiety, and have deficits in coping (Kashdan et al., 2005). Individuals with more fragile self-esteem and emotional instability may also be more vulnerable to vicarious traumatisation in the workplace (Bontempo \& Malcolm, 2012).

The global results of this international study regarding self-esteem in particular, marry well with the findings of Bontempo and Napier (2011) with regards to their study of the emotional stability of Australian signed language interpreters. In that study of 110 accredited Auslan/English interpreters, the psychological constructs of self-efficacy, goal orientation and negative affectivity were measured, as were interpreter ratings of selfperceived competence as practitioners. The most significant finding revealed the dimension of emotional stability (represented on the negative end of the continuum by traits of anxiety and neuroticism, and measured in that study by the negative affectivity scale) as a strong predictor of interpreter's selfperceived competence.

In this study, we also had a look at the correlation between self reported competence as an interpreter and the actual level of accreditation held (only in those countries where we were able to confirm accreditation standards and practices), and found a moderately strong correlation of .35 between level of accreditation held and level of self-rated competence, with Australia $(r=$ 
$.378)$ and Canada $(r=.366)$ slightly more accurate at self-rating competence when matched against the actual certification held. The UK $(r=.288)$ and the US $(r=.251)$ were close behind.

\subsection{Australian and US data}

Now that we have contextualized the study by reporting on relevant global results, we give an overview of the specific data from Australia and the US and the most significant predictors.

4.2.1 Demographics. The demographic picture of the 205 Australian responses revealed 170 female $(83 \%)$ and 32 male (16\%) interpreters, with 3 of unreported gender $(1 \%)$. Six percent reported being deaf interpreters and 94\% were hearing Auslan/English interpreters. The largest age grouping was in the range of 35-39 years old. The average age of the respondents was 42 years old, and $63 \%$ had completed a formal interpreter education program.

Of the 1,224 responses from the US 1,078 (88\%) were female, 134 $(11 \%)$ were male, and $12(1 \%)$ did not report their gender. Deaf interpreters made up 3\% (36) of the respondents, as compared to 97\% (1188) hearing ASL/English interpreters. The largest age grouping was slightly higher than the Australians at 40-44 years (with 41.3 years the average age), and an equivalent percentage of $62 \%$ (755/1224) of US respondents had completed a formal interpreter education program.

4.2.2 General predictors. Reliabilities (alpha) for the variables of selfesteem and perfectionism among Australian respondents were .86. Scores for the Big Five inventories were .87 or higher, therefore all the Australian survey responses had strong reliability. We found a positive correlation between emotional stability and self-esteem scales for the Australian respondents $(\mathrm{r}=.511)$.

Reliabilities (alpha) for the variables of self-esteem and perfectionism among US respondents were .875 and .85. Scores for the Big Five inventories were .88 or higher, meaning all the US survey responses also had strong reliability. As with the Australian respondents, we found a positive correlation between emotional stability and self-esteem scales $(\mathrm{r}=.52)$.

4.2.3 Age. Age was significantly correlated with self-ratings of higher levels of interpreter competence among both the Australian and US respondents (Australian: $r=.217$, US: $r=.17$ ). For Australian interpreters, four personality variables were significantly correlated to ratings of sign language proficiency: self-esteem (.252); conscientiousness (.241); emotional stability (.162); and perfectionism (.126). For the US interpreters, however, five personality variables were significantly correlated to ratings of sign language proficiency: self-esteem (.20); conscientiousness (.06); emotional stability (.11); extraversion (.16); and openness to experience (.18). The first three variables were the same as the Australians, but perfectionism did not appear to be significant for American interpreters. Age alone accounted for $4 \%$ of the variance.

4.2.4 Competence. An extrinsic measure of competence was the level of accreditation reported by the respondents. So, we analysed self-rated competence with all the personality variables as predictors. For Australian interpreters, self-esteem and conscientiousness were retained as significant predictors with a multiple R of .390. But for US interpreters, self-esteem and openness to experience were retained as significant predictors with a multiple R of .280.

Experience was a huge predictor of competence. When we added experience to the analysis, results in experience plus self-esteem and 
conscientiousness accounted for $26 \%$ of the variance, with experience as the number one predictor. That is, the more experienced the respondent, the more likely they were to rate themselves as competent practitioners, and they also scored highly in terms of their self-esteem and conscientiousness.

\section{Discussion}

A significant amount of the variance in the ratings of perceived competence in the global data, and more specifically in the Australian and US data, can be accounted for by the constructs of self-esteem, openness to experience, and conscientiousness predictors. That is, these three constructs were the strongest indicators in relation to predicting competence amongst signed language interpreters in this study. In addition, the self esteem scale of this study and the trait of emotional stability were found to be closely linked, reinforcing the previous findings of Bontempo and Napier (2011) regarding emotional stability as a predictor of interpreter competence.

Dörnyei (2005, p. 24) notes in relation to the strength of personality variables that "even carefully executed studies rarely manage to explain more than about $15 \%$ of the variance" and goes on to state that personality simply doesn't explain the whole picture, "since personality variables act as powerful modifying variables". When taking the additive effect of personality on top of general cognitive ability into account, we see potentially very powerful predictors of interpreter performance. Thus it would seem that, in order to predict successful performance in signed language interpreters, personality variables are important ingredients in the theoretical 'pie'.

So what does this actually mean in practice? It means that if interpreter educators can potentially measure any individual and obtain information about the relevant aspects of their personality and their general mental/cognitive ability, then they are in a far stronger position to predict the individual's likelihood of success as an interpreting student than if they do not have that information. Essentially, educators can then take a gamble, weighing up what they know about about the individual based on the measurements and predict whether they will be a good interpreter.

We know that the predictability of occupational success is reliable based on personality and general mental ability measurements that have been conducted across thousands of studies looking at general job performance (Penney et al., 2011; Tews et al., 2010). As personality variables have been closely examined in relation to job performance in other occupations, it is possible to make assertions about what predictors can be observed in general populations and to apply these to other workplace contexts. We can also connect this reasoning to signed language interpreting, and predict how personality variables will play out for individual interpreters or interpreting students.

Based on the data from this study, we know with a level of confidence that if a sign language interpreting student, or an interpreter, has good general mental ability, and rates highly on self-esteem, conscientiousness, emotional stability and openness, they are in a strong position to succeed in this profession. Putting aside the language (technical) aspects and the physical requirements of being an interpreter, this information offers a standard point of reference in interpreter training, for interpreter development, management of health and well being, and so on.

\subsection{Implications}

The data presented here has implications for interpreter employment, whereby employers could match their employees to particular assignments 
more carefully; they could assign team mates for interpreting jobs in a way to obtain a better outcome; and with regard to managing performance through organising supervision or mentoring to build trust and enhance relationships with colleagues. More broadly, we can also relate these findings to the risk of occupational stress, burnout, vicarious trauma and overuse syndrome, which are issues commonly experienced by signed language interpreters (Bontempo \& Malcolm, 2012; Clare, 2000; Dean \& Pollard, 2001; Fischer \& Woodcock, 2012; Madden, 2005; McCartney, 2006; Schwenke, 2010; Woodcock \& Fischer, 2008), and may be exacerbated by high levels of certain personality traits, such as perfectionism (Schwenke, 2012). Using findings such as those presented in this paper can assist us to work with interpreters to develop strategies or coping resources for building resilience; assessing how to accept assignments; developing insight into the self; and managing physical, mental and emotional stress levels.

The results of this study have implications for interpreter education programs in terms of: screening applicants for appropriate selection; providing a low anxiety classroom environment; and acknowledging that students are concerned about public self-preservation and the potential impact on self-esteem from the fall-out of interpreter education program content. There is an evaluative 'threat' that exists for interpreting students as they have to function within an assessment heavy environment (live role plays, exams, etc.), and their perceptions of self-worth could be preserved or damaged on the basis of performance feedback in interpreting classes or on the job with colleagues (Thompson, 1994).

Previous research has shown that, generally, anxious students do not learn as quickly as relaxed students. For example, Hembree (1988) found that the lower the students' ability (real or perceived), the higher the level of test anxiety. Thus, appropriate sequencing of instructional tasks can minimise any uncertainty in the learning processes and increase experiences of success. Uncertainty can be minimized by simple things, such as providing assessment details and rubrics at the start of a course, so that students know the achievement expectations and contexts. The more relaxed the student, the more open they will be to learning.

Dweck et al (1988) confirm teachers' evaluative feedback holds power and the potential to enhance student achievement, which can otherwise be limited by negative affect and self-defeating thought patterns. Young (1991) also suggests that teachers assess their error correction approach as students need to understand that mistakes are part of the learning process, and everyone makes mistakes - it is not possible to be perfect, and with regard to interpretation - there is rarely one way to interpet something. If teachers project the belief that students will achieve their goal, they can counter balance experiences of frustration by involving students in confidence building tasks.

Dörnyei (1994) suggests that SLA educators should:

- help students develop realistic expectations of what can be achieved in a given period;

- $\quad$ highlight what students can do, not just what they cannot do;

- encourage the view that mistakes are part of learning;

- help students recognise links between effort and outcome, and attribute past failures to (where applicable) confusion about what to do or the use of inappropriate strategies, rather than a complete lack of ability as this may lead to learned helplessness;

- encourage students to set attainable sub-goals;

- discuss with students the choice of teaching materials and text types, allowing some choice / latitude where appropriate; and 
- be empathic, congruent and accepting, taking on the role of facilitator rather than an authority figure.

Being aware of the personality of interpreting students and how to accommodate for this on courses, and for employers, in the place of work, is potentially invaluable for ultimately getting the best out of people. Measuring personality variables may provide awareness of students' potential capabilities, and by adopting Dörnyei's recommended practices in SLA teaching into pedagogical practices in interpreter education, this may help not only to encourage students to be open to learning and reduce their anxiety/ stress levels, but also to produce interpreting graduates that are better able to cope with the demands of the interpreting profession and thus lead to greater job performance.

If the goal of personality research is to identify the interconnections between people, behaviour and situations, then once those connections are identified, we have a responsibility as educators and employers of interpreters to be mindful of these factors in managing students and staff. Teachers can and should help students develop a sense of self efficacy and confidence by providing meaningful, achievable and success-engendering interpreting and language tasks.

Our data indicates dispositional feelings of self-worth impact on perceived interpreter competence, and that perceived level of competence correlates with actual level of interpreter accreditation. Our findings, like most research, merely offer reinforcement for the existing intuitive beliefs of many interpreter practitioners, educators and researchers. In this case it is about 'what makes a competent interpreter': we are not claiming any major discovery.

Anyone who has taught interpreters knows without research to provide empirical evidence, that personality makes a difference in the learning environment and the workplace (personality of the teacher/employer and personality of the student/employee). This is clearly something that deaf people have recognised and commented on for many years in interviews about 'what makes a good interpreter' (see for example Napier, 2011a; Napier \& Barker, 2007), where they report that the technical skills of an interpreter in some situations matters far less than the personality and attitude of the interpreter in that situation.

Educators and employers can reflect upon, recognise and respond to these findings regarding interpreter personality in ways that make a difference to students and staff: a focus on the affective implications of interpreter training and the nature of the work, can only help, not hinder interpreter development (in our humble opinion).

We envisage that our findings will go some way towards giving people permission to feel that giving consideration to disposition does have legitimacy in the work that we do as educators, interpreters and employers of practitioners, as consumers of interpreting services, and that understanding more about interpreter personality assists us in continuing to look for ways to determine aptitude for; and to maximise the abilities of, people training for, entering into, or already in, our field of work; and broadening our horizons, and theirs, in the process.

\section{Limitations of the study}

A report on a study such as this one would not be complete without recognition of the inherent limitations that may have skewed the findings. Firstly, it is important to acknowledge that the respondents recorded their ratings of perceived competence as an interpreter, we did not measure actual performance, and we had no way of checking if their self-assessment was 
correct. There was also the potential for sampling error in that, compared to other studies of occupational performance and personality, this was a small sample size (although with over 2000 respondents, it was much larger than many previous personality studies undertaken in the signed language interpreting field).

Another consideration is that people who respond to surveys such as these may have more of a vested interest in participating, potentially impacting on responses. Being social research, there may have also been a social-desirability bias that affected the responses of participants. Some of the mitigating factors for social desirability responses, however, would be that the respondents knew the survey was anonymous; there was no impact on their work, salary, promotion, etc. in returning the survey, so there was no need to rate proficiency in a falsifying fashion; and the fact that lower ratings of competence matched up with lower levels of accreditation suggests there was a trend towards honesty amongst participants, rather than a social ideal.

Additional limitations of the study was the length and detail of questionnaires, which may have put people off completing the full instrument or from participating in the study in the first place, and the veracity of all self-report measures can be problematic. Nevertheless, these are possible flaws of all social research survey design, and are not unique to this study.

\section{Conclusion}

To revisit our hypotheses, our findings indicate that competent interpreters:

1. have higher self-esteem globally - this was also the case in Australia, NZ, UK, Canada and in the US;

2. are higher in conscientiousness in Australia;

3. are more emotionally stable;

4. are slightly more extraverted - in the US sample only;

5. rate higher in openness to experience globally, and in the US;

6. do not rate more highly in agreeableness;

7. are moderately inclined towards perfectionism - in the global data only.

In addition, age and experience were significantly correlated with higher levels of interpreter competence.

With regard to our research questions then, personality does play a role in predicting job performance for sign language interpreters, and the specific aspects of personality that are most predictive can be identified. Our final research question alluded to whether it was possible to build an assessment profile or tool to use to screen for sign language interpreter aptitude and suitability. It would appear this is possible, it may however be too early to be definitive about the contents and application of a personality screening assessment for sign language interpreter use to determine occupational suitability. More research in this area is warranted, and any introduction of screening measures in relation to interpreter personality should be carefully executed and analysed. Documenting and reporting on results and developments in this regard is strongly recommended for the interpreting field.

The findings of this study undoubtedly reveal that self-esteem and emotional stability, openness to experience and conscientiousness are important predictors of sign language interpreter competence, reinforcing the findings in the broader scholarly literature in organisational psychology, and 
supporting recent findings in studies of interpreter aptitude. Indeed, personality does matter.

\section{Acknowledgements}

Sincere thanks to all the study participants for their contribution to our increased understanding of interpreter personality - we appreciate your taking the time to participate in our research. Our gratitude is extended to Dr Jerry Palmer of Eastern Kentucky University for his expert assistance with the statistical analysis of the considerable bank of data collected in this study. 


\section{References}

Arjona-Tseng, E. (1994). Psychometric selection tests. In Silvie Lambert \& Barbara Moser-Mercer (Eds.), Bridging the Gap (pp. 69-86).

Amsterdam: John Benjamins.

Barrick, M. R., \& Mount, M. K. (2005). Yes, personality matters: Moving on to more important matters. Human Performance, 18, 359-372.

Barrick, M. R., Mount, M. K., \& Judge, T. A. (2001). Personality and performance at the beginning of the new millennium: What do we know and where do we go next? Personality and Performance, 9, 9-30.

Bontempo, K., \& Malcolm, K. (2012). An ounce of prevention is worth a pound of cure: Educating interpreters about the risk of vicarious trauma in healthcare settings. In K. Malcolm \& L. Swabey (Eds.), In our hands: Educating healthcare interpreters (pp. 105-130). Washington DC: Gallaudet University Press.

Bontempo, K., \& Napier, J. (2007). Mind the gap! A skills gap analysis of sign language interpreters. The Sign Language Translator \& Interpreter, 1, 275-299.

Bontempo, K., \& Napier, J. (2009). Getting it right from the start: Program admission testing of signed language interpreters. In C. Angelleli \& H. Jacobson (Eds.), Testing and Assessment in Translation and Interpreting. Amsterdam: John Benjamins.

Bontempo, K., \& Napier, J. (2011). Evaluating emotional stability as a predictor of interpreter competence and aptitude for interpreting. Interpreting, 13, 85-105.

Bouchard, T. J., \& Loehlin, J. C. (2001). Genes, evolution and personality. Behaviour Genetics, 31(3), 243-273.

Bozionelos, N. (2004). The relationship between disposition and career success: A British study. Journal of Occupational and Organisational Psychology, 77, 403-420.

Brien, D., Brown, R., \& Collins, J. (2002). The organisation and provision of British Sign Language/ English Interpreters in England, Scotland and Wales. London: Department for Work and Pensions, British Government \& Durham University.

Campbell, S., \& Hale, S. (2003). Translation and interpreting assessment in the context of educational measurement. In Gunilla, M. Anderman, \& Margaret Rogers (Eds.), Translation today: Trends and perspectives (pp. 205-220). Clevedon: Multilingual Matters. .

Clare, K. (2000). Vicarious traumatisation of Australian Sign Language interpreters working in a legal setting. (Masters dissertation, La Trobe University, Melbourne).

Clifford, A. (2005). Putting the exam to the test: Psychometric validation and interpreter certification. Interpreting, 7, 97-131.

Cokely, D. (1981). Sign language interpreters: A demographic survey. Sign Language Studies, 32, 261-286.

Dean, R., \& Pollard, R. Q. (2001). The application of demand-control theory to sign language interpreting: Implications for stress and interpreter training. Journal of Deaf Studies and Deaf Education, 6, 1-14.

Dodds, J. (1990). On the aptitude of aptitude testing. The Interpreters' Newsletter, No. 3. EUT - Edizioni Università di Trieste.

Dörnyei, Z. (1994). Motivation and motivating in the foreign language classroom. Modern language journal, 78, 273-284.

Dörnyei, Z. (2005). The psychology of the language learner: Individual differences in second language acquisition. Mahwah, NJ: Lawrence Erlbaum.

Dua, J. K. (1993). The role of negative affect and positive affect in stress, depression, self- esteem, assertiveness, Type A behaviors, 
psychological health, and physical health. Ge netic, Social and General Psychology Monographs, 119(4), 515-552.

Dweck, C. S., \& Leggett, E. L. (1988). A social-cognitive approach to motivation and personality. Psychological Review, 95, 256-273.

Eysenck, M. W. (1979). Anxiety, learning and memory: A reconceptualization. Journal of Research in Personality, 13, 363-385.

Fischer, S. L., \& Woodcock, K. (2012). A cross-sectional survey of reported musculoskeletal pain, disorders, work volume and employment situation among sign language interpreters. International Journal of Industrial Ergonomics, 42, 335-340.

Fouad, N. A. (2007). Work and vocational psychology: Theory, research and applications. Annual Review of Psychology, 58, 543-564

Frishberg, N. (1990). Interpreting: An introduction. Silver Spring, MD: RID Publications.

Gardner, R. C., Smythe, P. C., Clement, R., \& Gliksman, L. (1976). Second language acquisition: A social psychological perspective. Canadian Modern Language Review, 32, 198-213.

Gardner, R. C., Smythe, P. C., \& Lalone, R. N. (1994). The nature and replicability of factors in second language acquisition (Research bulletin \#605). London, Ontario: University of Western Ontario.

Gerver, D., Lumley, P. E., Long, J., \& Lambert, S. (1984). Selecting trainee conference interpreters: A preliminary study. Journal of Occupational Psychology, 57(1), 17-31.

Gerver, D., Longley, P. E., Long, J., \& Lambert, S. (1989). Selection tests for trainee conference interpreters. Meta, 34(4), 724-735.

Goldberg, L. R. (1990). An alternative "Description of Personality": The Big-Five Factor Structure. Journal of Personality and Social Psychology, 59, 1216-1229.

Gomez, M. L., Molina, T. B., Benitez, P. P. \& Santiago de Torres, J. (2007). Predicting proficiency in signed language interpreting: A preliminary study. Interpreting, 9, 71-93.

Grbic, N. (2007). Where Do We Come From? What Are We? Where Are We Going? A Bibliometrical Analysis of Writings and Research on Sign Language Interpreting. The Sign Language Translator \& Interpreter, 1, 15-51.

Guion, R. M., \& Highhouse, S. (2004). Essentials of Personnel Assessment and Selection. New York: Psychology Press.

Hale, S., \& Napier, J. (2013). Research Methods in Interpreting: A Practical Resource. London: Bloomsbury.

Hembree, R. (1988). Correlates, causes, effects, and treatment of test anxiety. Review of Educational Research, 58, 7-77

Hewitt, P. L., \& Flett, G. L. (1991). Perfectionism in the self and social contexts: conceptualization, assessment, and association with psychopathology. Journal of Personality and Social Psychology, 60, 456-70.

Holroyd, K. A., \& Appel, M. A. (1980). Test anxiety and physiological responding. In I. G. Sarason (Ed.), Text anxiety: Theory, research and applications (pp. 129-151). Hillsdale, NJ: Erlbaum.

Humphrey, J., \& Alcorn, B. (1996). So you want to be an interpreter? An introduction to sign language interpreting. Amarillo, Texas: $\mathrm{H} \& \mathrm{H}$ Publishers.

Judge, T. A., \& Bono, J. E. (2001). Relationship of Core Self-Evaluations Traits - self esteem, generalized self-efficacy, locus of control and emotional stability - with job satisfaction and job performance: A metaanalysis. Journal of Applied Psychology, 86(1), 80 - 92. 
Judge, T. A., Higgins, C. A., Thoresen, C. J., \& Barrick, M. R. (1999). The Big Five personality traits, general mental ability, and career success across the life span. Personnel Psychology 52, 621-652.

Kalina, S. (2002). Quality in interpreting and its prerequisities: A framework for a comprehensive view. In G. Garzone \& M. Viezzi (Eds.), Interpreting in the $21^{\text {st }}$ Century: Proceedings of the $1^{\text {st }}$ conference on interpreting studies, Forli, University of Bologna, 9-11 Nov. 2000 (pp. 121 - 130). Amsterdam: John Benjamins. .

Krashen, S. (1976). Formal and informal linguistic environments in language acquisition and language learning. TESOL Quarterly, 10, 157-168.

Lambert, S. (1991). Aptitude testing for simultaneous interpretation at the University of Ottawa. Meta 36(4), 586-594.

Lau, V.P., \& Shafffer, M.A. (1999). Career success: The effects of personality. Career Development International, 4(4), 225-230.

Leeson, L. (2008). Signed language interpreting. In M. Baker \& G. Saldanha (Eds.), Routledge Encyclopedia of Translation Studies (2nd Ed., pp. 274-279). New York: Routeledge.

McIntyre, P. D. (1995. How does anxiety affect second language learning? A reply to Sparks and Ganschow. The Modern Language Journal, 79(1), 90-99.

McIntyre, P. D., \& Gardner, R. C. (1991). Language anxiety: Its relation to other anxieties and to processing in native and second languages. Language learning, 41, 513-534.

Macnamara, B. (2009). Foundational cognitive aptitudes of sign language interpreters. Journal of Interpretation, 9-32.

Macnamara, B., Moore, A., Kegl, J., \& Conway, A. (2011). Domain-general cognitive abilities and simultaneous interpreting skill. Interpreting, 13, 121-142.

Madden, M. (2005). The prevalence of occupational overuse syndrome in signed language interpreters in Australia - What a pain! In M. Metzger $\&$ E. Fleetwood (Eds.), Attitudes, innuendo, and regulators: Challenges of interpretation (pp. 3-70). Washington, DC: Gallaudet University Press..

McCartney, J. (2006). Burnout of sign language interpreters: A comparative study of K-12, postsecondary and community interpreters. Journal of Interpretation, 47-82.

McCrae, R. R., \& Costa, P. T., Jr. (1999). A Five-Factor Theory of personality. In L. A. Pervin \& O. P. John (Eds.), Handbook of personality: Theory and research (2nd ed., pp. 139-153). New York: Guilford Press.

McCrae, R. R., \& Costa, P. T., Jr. (2003). Personality in adulthood: A FiveFactor Theory perspective (2nd. ed.). New York: Guilford Press.

Metzger, M. (2006). Salient studies of signed language interpreting in the context of community interpreting scholarship. Lingusitica Antverpiensia, 5, 263-291.

Moser-Mercer, B. (1985). Screening potential interpreters. Meta, 30(1), 97100.

Moser-Mercer, B. (1994). Aptitude Testing for Conference Interpreting: Why, When and How. In Silvie Lambert \& Barbara Moser-Mercer (Eds.), Bridging the Gap (pp. 57-68). Amsterdam: John Benjamins.

Motowildo, S. J., Borman, W. C., \& Schmit, M. J. (1997). A Theory of Individual Differences in Task and Contextual Performance. Human Performance, 10(2), $71-83$.

Mount, M. K., \& Barrick, M. R. (1998). Five reasons why the "Big Five" article has been frequently cited. Personnel Psychology, 51, 849-857. 
Mount, M. K., Barrick, M. R., \& Stuart, G. L. (1998). Five-Factor Model of personality and Performance in Jobs Involving Interpersonal Interactions. Human Performance, 11(2), $145-165$

Napier, J. (2011a). "It's not what they say but the way they say it." A content analysis of interpreter and consumer perceptions of signed language interpreting in Australia. International Journal of the Sociology of Language, 207, 59-87.

Napier, J. (2011b). Signed language interpreting. In K. Windle \& K. Malmkjaer (Eds.), The Oxford Handbook of Translation Studies. Oxford: Oxford University Press.

Napier, J. (2012). Sign language interpreting research. In C. A. Chapelle (Ed.), The Encyclopedia of Applied Linguistics. Wiley-Blackwell.

Napier, J., \& Barker, R. (2003). A demographic survey of Australian Sign Language interpreters. Australian Journal of Education of the Deaf, 9, 19-32.

Napier, J., McKee, R., \& Goswell, D. (2006). Sign language interpreting: Theory and practice in Australia and New Zealand. Sydney: Federation Press.

Napier, J., McKee, R., \& Goswell, D. (2010). Sign language interpreting: Theory and practice in Australia and New Zealand. Sydney: Federation Press.

Napier, J. \& Rohan, M. (2007). An invitation to dance: Deaf consumers' perceptions of signed language interpreters and interpreting. In M. Metzger \& E. Fleetwood (Eds.), Translation, sociolinguistic, and consumer issues in interpreting. Washington, DC: Gallaudet University Press.

Nave, C. S., Sherman, R. A., Funder, D.C., Hampson, S. E., \& Goldberg, L. R. (2010). On the contextual independence of personality: Teachers' assessments predict directly observed behaviour after four decades. Social psychological and personality science, 3(1), 1-9.

Neumann Solow, S. (1981). Sign language interpreting: A basic resource book. Silver Spring, MD: National Association of the Deaf.

Neumann Solow, S. (2000). Sign language interpreting: A basic resource book. Burtonsville, MD: Linstok Press.

Oakes, D. W., Ferris, G. R., Martocchio, J. J., Buckley, M. R., \& Broach, D. (2001). Cognitive ability and personality predictors of training program skill acquisition and job performance. Journal of Business and Psychology, 15(4), 523-548.

Ones, D. S., Dilchert, S., Viswesvaran, C., \& Judge, T. A. (2007). In support of personality assessment in organizational settings. Personnel Psychology, 60(4), 995-1027.

Penney, L. M., David, E., \& Witt, L. A. (2011). A review of personality and performance: Identifying boundaries, contingencies, and future research directions. Human Resource Management Review, 21, 297-310.

Pöchhacker, F. (2011). Assessing aptitude for interpreting: The SynCloze test. Interpreting, 13, 106-120.

Reeve, C. L., \& Heggestad, E. D. (2004). Differential relations between general cognitive ability and interest-vocation fit. Journal of Occupational and Organisational Psychology, 77, 385-402.

Rice, K. G., \& Slaney, R. B. (2002). Clusters of perfectionists: Two studies of emotional adjustment and academic achievement. Measurement and Evaluation in Counseling and Development, 35, 35-48.

Rosenberg, M. (1965). Society and the adolescent self-image. Princeton, NJ: Princeton University Press.

Rudser, S. F., \& Strong, M. (1986). An examination of some personal characteristics \& abilities of sign language interpreters. Sign Language Studies, 53, 315-331. 
Russo, M. (1993). Testing Aptitude for Simultaneous Interpretation: Evaluation of the First Trial and Preliminary Results. The Interpreters' Newsletter, 5, 68-71.

Russo, M. (2011). Aptitude testing over the years. Interpreting, 13, 5-30.

Russo, M., \& Pippa, S. (2004). Aptitude to Interpreting: Preliminary Results of a Testing Methodology Based on Paraphrase. Meta, 49(2), 409-432.

Sawyer, D. (2004). Fundamental aspects of interpreter education: Curriculum and assessment. Amsterdam: John Benjamins.

Schein, J. (1974). Personality characteristics associated with interpreter proficiency. Journal of Rehabilitation of the Deaf, 7, 33-43.

Schein, J., \& Yarwood, S. (1990). The status of interpreters for deaf Canadians. The ACEHI Journal, 16, 127-141.

Schmidt, F. L. (2002). The Role of General Cognitive Ability and Job Performance: Why There Cannot Be a Debate. Human Performance, 15(1), $187-210$.

Schmidt, F. L., \& Hunter, J. E. (1998). The validity and utility of selection methods in personnel psychology: Practical and theoretical implications of 85 years of research findings. Psychological Bulletin, 124 (2), 262274.

Schwenke, T. (2010). Sign language interpreters and burnout. Journal of Interpretation, 31-54.

Schwenke, T. (2012). The relationships between perfectionism, stress, coping resources, and burnout among sign language interpreters. Counseling and Psychological Services Dissertations. Retrieved from http://digitalarchive.gsu.edu/cps_diss/80

Seal, B. C. (2004). Psychological Testing of Sign Language Interpreters. Journal of Deaf Studies \& Deaf Education, 9, 39 - 52.

Shaw, S. (2011). Cognitive and motivational contributors to aptitude: A study of spoken and signed language interpreting students. Interpreting, $13,70-84$.

Shaw, S., \& Hughes, G. (2006). Essential characteristics of sign language interpreting students: Perspectives of students and faculty. Interpreting 8(2), 195-221.

Schlesinger, M., \& Pöchhacker, F. (2011). Aptitude for interpreting. Interpreting, 13, 1-4.

Snow, R.E. (1992). Aptitude theory: Yesterday, today, and tomorrow. Educational Psychologist, 27, 5-32.

Stauffer, L, \& Shaw, S. (2006). Personality characteristics for success in interpreting courses: Perceptions of spoken and sign language interpretation students. Journal of Interpretation, 11-24.

Stewart, D., Schein, J., \& Cartwright, B. E. (1998). Sign language interpreting: Exploring its art and science. Boston: Allyn and Bacon.

Tews, M. J., Michel, J. W., \& Lyions, B. D. (2010). Beyond personality: The impact of GMA on performance for entry-level service employees. Journal of Service Management, 21, 344 - 362.

Thompson, T. (1994). Self-worth protection: Review and implications for the classroom. Educational Review, 46(3), 259-274.

Timarová, S., \& Salaets, H. (2011). Learning styles, motivation and cognitive flexibility in interpreter training: Self-selection and aptitude. Interpreting, 13, 31-52.

Timarová, S., \& Ungoed-Thomas, H. (2008). Admission testing for interpreting courses. The Interpreter and Translator Trainer, 2, 29-46.

Wang, J. (2013). Bilingual working memory capacity in professional Auslan/English interpreters. Interpreting, 15(2), 139-167.

Wang, J., \& Napier, J. (2013). Signed language working memory capacity of signed language interpreters and deaf signers. Journal of Deaf Studies \& Deaf Education, 18, 271-286. 
Watson, D., Suls, J., \& Haig, J. (2002). Global self-esteem in relation to structural models of personality and affectivity. Journal of Personality and Social Psychology, 83, 185-197.

Woodcock, K., \& Fischer, S. L. (2008). Occupational health and safety for sign language interpreters. Toronto, ON: Ryerson University.

Young, D, J. (1991. Creating a low-anxiety classroom environment: What does language anxiety suggest? The Modern Language Journal, 75(4), 426-439.

Zannirato, A. (2008). Teaching interpreting and interpreting teaching: A conference interpreters' overview of second language acquisition. In John Kearns (Ed.), Translator and Interpreter Training (pp. 19-38). London: Continuum. 